\title{
Effect of sweeteners and storage on compositional and sensory properties of blackberry jams
}

\author{
Csilla Benedek ${ }^{1} \cdot$ Zsanett Bodor $^{2} \cdot$ Vanda Tímea Merrill $^{3} \cdot$ Zoltán Kókai $^{4} \cdot$ Attila Gere $^{4} \cdot$ Zoltan Kovacs $^{2}$. \\ István Dalmadi ${ }^{5}$. László Abrankó 6
}

Received: 28 February 2020 / Revised: 2 July 2020 / Accepted: 4 July 2020 / Published online: 19 July 2020

(C) The Author(s) 2020

\begin{abstract}
Sweeteners of natural sources, such as sugar alcohols, are in the centre of growing interest. Their impact on the phytochemicals, antioxidant and sensory properties of blackberry jams were investigated during a 9-months storage period. Measurements on jams prepared with different sugars and sugar alcohols (sucrose, fructose, xylitol and erythritol) were performed at the date of preparation and in the 1st, 3rd, 6th, 9th month.

Total polyphenol content, individual polyphenols, antioxidant properties, anthocyanin content and CIE $L^{*} a^{*} b^{*}$ colour were determined. Sensory profiles were determined by a trained panel. Sensory attributes were compared by the results of the electronic tongue and nose.

Sweeteners had a significant impact on physicochemical properties and sensory attributes. Storage time also affected the sensory and compositional properties of jams. Changes in antioxidant properties did not follow a clear trend during the storage period, and antioxidant capacity was not affected significantly by the sweetening agent, but showed a significant decline from the 6th month. A positive effect of xylitol was observed in terms of a low degradation rate of anthocyanins, while their decomposition was the fastest in the fructose-containing preparation. Jams sweetened with erythritol reached significantly lower values for some sensory attributes (blackberry flavour and general taste intensity), however, they showed more intense red colour. Multiple factor analysis enabled the identification of the effect of sweetener and storage time on the pattern of the sensory data matrix. Classification according to individual sweeteners was performed successfully by the electronic tongue, but not by electronic nose.
\end{abstract}

Keywords Blackberry jam $\cdot$ Sweetener $\cdot$ Sugar alcohol $\cdot$ Polyphenol $\cdot$ Sensory analysis $\cdot$ Multiple factor analysis

Csilla Benedek

benedek.csilla@se-etk.hu

1 Faculty of Health Sciences, Department of Dietetics and Nutrition, Semmelweis University, Vas u. 17, 1088 Budapest, Hungary

2 Faculty of Food Science, Department of Physics and Control, Szent István University, Budapest, Hungary

3 Faculty of Health Sciences, Department of Dietetics and Nutrition, Semmelweis University, Budapest, Hungary

4 Faculty of Food Science, Department of Postharvest and Sensory Evaluation, Szent István University, Budapest, Hungary

5 Faculty of Food Science, Department of Refrigeration and Livestock Products' Technology, Szent István University, Budapest, Hungary

6 Faculty of Food Science, Department of Applied Chemistry, Szent István University, Budapest, Hungary

\section{Introduction}

Sugar substitutes, especially natural sweeteners are getting more popular, in accordance with the trends of modern nutrition. Products with reduced energy or sugar content, as well as sugar-free products made with sugar alcohols are very successful on the market, which can be partly explained by the increasing consumer aversion towards artificial additives, including intensive sweeteners. They are also used on a large scale by the food industry due to their favourable sensory attributes and good technological properties as thickeners or humectants; they are resistant to heat and $\mathrm{pH}$ changes and are not involved in Maillard reaction. Although sugar alcohols are not a health concern for healthy individuals, showing some potential health benefits [1], undesired effects as bloating and diarrhoea may appear at some people at the consumption of high doses, especially those suffering of 
bowel problems. Nevertheless, xylitol and erythritol are reported to be more tolerable than sorbitol or mannitol. Safety of polyols is currently being re-evaluated by the European Food Safety Authority, this re-evaluation is planned to be completed by the end of 2020 [2]. As a sweetener alternative, fructose is still markedly present on the market of diabetic products as a low-cost sweetener with a low glycaemic index (GI). Its insulin-independent metabolism takes place directly in the liver, acting as a major mediator in the development of non-alcoholic fatty liver disease [3]. Due to the above-mentioned health-related limitations, the use of sugar alcohols, and especially fructose, requires due foresight.

Berries and products containing berries, either in their fresh or preserved form, are popular amongst health-conscious consumers due to their high levels of bioactive compounds, especially polyphenols. Polyphenol-rich diet has been associated with a range of health benefits, including anti-inflammatory effects, improvement of the endothelial and vascular function, improvement of fasting serum glucose, as well as beneficial effects on the gut microbiome and modulation of energy metabolism. Thus, polyphenols are effective in optimizing cardiometabolic health and reduce risk factors of type II diabetes and the metabolic syndrome and may protect against cognitive decline and dementia [4-7].

There has been an increased concern over the past decades regarding the protection of nutritional values and quality optimization of processed foods, including the stabilization of polyphenols. At the same time, market trends clearly point towards preferences for low-calorie, sugar-free fruit preserves. Due to the favourable sensory and physiological properties of sugar alcohols, their combination with fruits is clearly present in the food industry. On the other hand, it is well known that the food matrix can also have a beneficial effect on berry anthocyanin stability [8]. However, the final colour of a food product containing anthocyanin-rich fruits is only partly determined by the initial anthocyanin content of the ingredient. Anthocyanin transformation and degradation occurring during food processing operations and storage are complex processes that can significantly influence the actual colour of the product. Stability of anthocyanins is influenced by their skeleton, $\mathrm{pH}$, light, temperature and the presence of complexing agents (proteins, metals) [9]. Thus, observed colour changes in processed foods are a composite result of various transformations of phenolic compounds in general, leading to yellowish or brownish pigments [10]. Darkening of the products is due to various oxidative reactions taking place during thermal treatment, such as oxidation of ascorbic acid or Maillard reaction, promoting dark pigments [11]. Thus, the overall colour alteration in thermally processed and stored products is probably due to a number of factors, such as degradation and polymerization of pigments (anthocyanins in case of berries), interactions with other components of the matrix (including co-pigmentation), oxidative reactions; i.e., mainly Maillard process and caramelising, and oxidation of tannins [9]. Therefore, processing operations should be optimized not only for food safety but also for the nutritional aspects. Properly designed and monitored processing and storage of processed foods are decisive in increasing shelf-life without altering their nutritional value, colour attributes, and functionality [10].

It is also known that phenolic compounds contribute to the sensory attributes of fruits as well, thus their alteration during processing and storage will have an impact on many of the sensory characteristics of fruit preserves, including flavour, aroma and colour [7]. Nevertheless, only limited information is available on the effect of sugar alcohols on the preservation of these bioactive substances present in fruits and the physicochemical changes occurring during heat treatment and subsequent storage of the preserved products [12].

In the present research, the impact of some sugars (sucrose, as reference and fructose) and sugar alcohols (xylitol and erythritol) was studied on several characteristics of blackberry jams during storage, i.e., phytochemical (total polyphenol and anthocyanin) content, in vitro antioxidant capacity, colour and sensory properties. Objectives also included a comparison of sensory properties obtained by instrumental (electronic nose and tongue) and sensory profile analysis.

\section{Material and methods}

\section{Materials}

Fresh blackberry, sweeteners and pectin, as well as jars and caps were purchased from local supermarkets. All solvents and reagents were supplied by Sigma-Aldrich, except for potassium persulfate (Acros Organics), hydrochloric acid (Carlo Erba) and distilled water. Crystalline polyphenols standards of caffeic acid, catechin, chlorogenic acid (5-caffeoyl-quinic acid, 5-CQA), epicatechin, ferulic acid, neochlorogenic acid (3-caffeoyl-quinic acid, 3-CQA), p-coumaric acid, quercetin-3-O-rutinoside (rutin) were purchased from Sigma-Aldrich/Merck (St. Louis, MI, USA), whereas cyanidin-glucoside (kuromanin), cyanidinrutinoside (keracyanin), quercetin and quercetin-3-O-glucoside from Extrasynthese (Genay, France). High purity water (Type1) was supplied by a Meck/Millipore ElixSynergy water purification station. LC-MS grade formic acid and UHPLC-MS grade acetonitrile were purchased from VWR (Radnor, USA). 


\section{Jam preparation and storage}

Sweeteners, according to their sweetening power, were added to $1500 \mathrm{~g}$ of fresh fruit [13], i.e., $500 \mathrm{~g}$ sucrose (100\%), $475 \mathrm{~g}$ fructose (105\%), $500 \mathrm{~g}$ xylitol (100\%) and $715 \mathrm{~g}$ erythritol (70\%). $9 \mathrm{~g}$ pectin was also added to each preparation for consistency, then the mixtures were heated and boiled for $5 \mathrm{~min}$. The jams resulted were distributed into previously sterilized jars, turned upside down for $10 \mathrm{~min}$ and then sterilized in a thermostat at $90{ }^{\circ} \mathrm{C}$ for $30 \mathrm{~min}$ and left there overnight. The jams were stored at room temperature in semi-dark conditions, modelling household conditions for 9 months, opening one bottle at the 0th, 1st, 3rd, 6th and 9th months for instrumental and sensory analyses.

\section{Total soluble solids, total polyphenol, monomeric anthocyanin content and antioxidant properties of jams}

The percentage of soluble solids in terms of Brix was determined according to the Annex of EU Regulation 974/2014/ EU, using a Kern Optics ORD 2UM digital refractometer [14].

Total polyphenol content (TPC, results expressed as gallic acid equivalents, GAE) [15] and total monomeric anthocyanin content ( $\mathrm{pH}$ differential method, results expressed as cyanidin-3-glucoside equivalents, using the molar absorptivity value $(\varepsilon)$ of $26,900 \mathrm{l} /\left(\mathrm{mol}^{*} \mathrm{~cm}\right)[16]$ and ABTS ${ }^{+}$radical ion scavenging antioxidant capacity [17] (results expressed as trolox equivalents, TE) were determined spectrophotometrically on a Thermo Helios- $\alpha$ spectrophotometer, using proper dilutions (usually tenfold) of the sample extracts. Analyses were performed in five replicates per sample, using a sample extract prepared by adapting the method reported by Garcia-Viguera et al. (1997) [18]. Briefly, $2.00 \mathrm{~g}$ of jam was extracted for $30 \mathrm{~min}$ in an ultrasound bath using $10 \mathrm{ml}$ of methanol:water:acetic acid 75:24.9:0.1. After centrifugation (5 min, $4000 \mathrm{rpm}$ ), the supernatant was separated, and the extraction was repeated. The two supernatants were collected, adjusting the final volume to $20 \mathrm{ml}$ with water. The average of the ten results (two extractions and five replicates and for each extract) was reported for each jam type (except for anthocyanin content, where three replicates were measured per extract).

\section{Colour determination}

Colorimetric measurements were determined in the CIE $L^{*} a^{*} b^{*}$ tristimuli coordinate system with a Konica Minolta CR410 colorimeter. The instrument was standardized against a reference white plate (CR-A44) before sample measurements. Jam samples were spread out at $1 \mathrm{~cm}$ depth on a Petri plate, and the $L^{*}, a^{*}, b^{*}$ values were measured in at several points of each sample, obtaining thus five replicates. $\Delta \mathrm{E}$ values were calculated according to the formula [19]:

$\Delta E=\sqrt{\left(\Delta L^{*}\right)^{2}+\left(\Delta a^{*}\right)^{2}+\left(\Delta b^{*}\right)^{2}}$

\section{Sensory profile analysis}

Sensory analyses were performed from freshly opened jars, at the date of preparation and at months 1,3,6, and 9, distributing the samples from the same jar among panel members after homogenization. Samples were put in transparent glass bowls with 3-digit random sample codes. A simplified profile analysis was applied during the sessions, i.e. the sensory descriptors (required by ISO 11,035) were previously established (Fig. 1) and the 12 panellists were given a complete list of the attributes [20]. Panellists were trained according to ISO 8586:2012 in the Sensory Laboratory of Szent István University [21]. The sensory tests were carried out meeting all the criteria of the relevant ISO standards [22, 23]. Sample characteristics were compared to internal reference values determined previously for the reference sample (sample containing sucrose). Neutral mineral water and neutral bakery products were used as taste neutralizers between evaluations. Values of sensory attributes were evaluated on a 0-100 unstructured line scale. At the end of the scoresheet, an open-ended textbox was provided to describe any additional perceptions, attributes. Panellists worked in individual booths, with standard lighting, while data was captured with ProfiSens software [24].

\section{Electronic tongue (ET) analysis}

Jam samples were analysed with the Alpha ASTREE potentiometric electronic tongue (ALPHA M.O.S., Toulouse, France). The sensor set composed of seven ISFET (ionsensitive field-effect transistor) sensors (ZZ, CA, BB, GA, $\mathrm{HA}, \mathrm{JB}, \mathrm{JE}$ ) that were designed to analyse and recognise the compounds in liquefied food [25]. The electronic tongue also contains a reference electrode $(\mathrm{Ag} / \mathrm{AgCl})$, and during the measurement the potential differences between the reference and each working electrodes are detected. Results are derived from the average of the last $10 \mathrm{~s}$ of the individual sensors. Jam samples were measured in nine replicates.

\section{Electronic nose (EN) analysis}

Headspace analysis of samples was performed by an NST3320 type electronic nose (Applied Sensor, A.G., Sweden) with a built-in headspace autosampler unit for 12 samples. The sample chamber contains 23 different sensors, software for collecting and processing the data of the specimen. The NST 3320 is provided with 10 MOS-FET 
Fig. 1 Sensory profile of the blackberry jams at the beginning (month 0) (a) and at the end (month 9) (b) of the period investigated

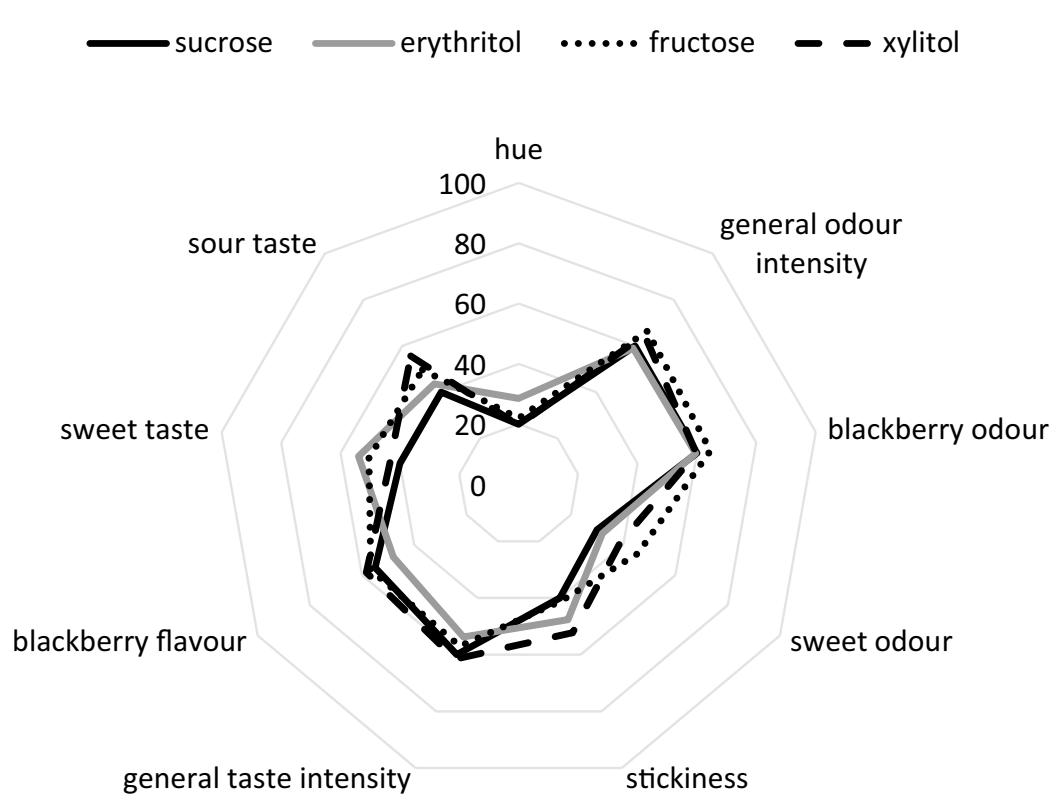

a

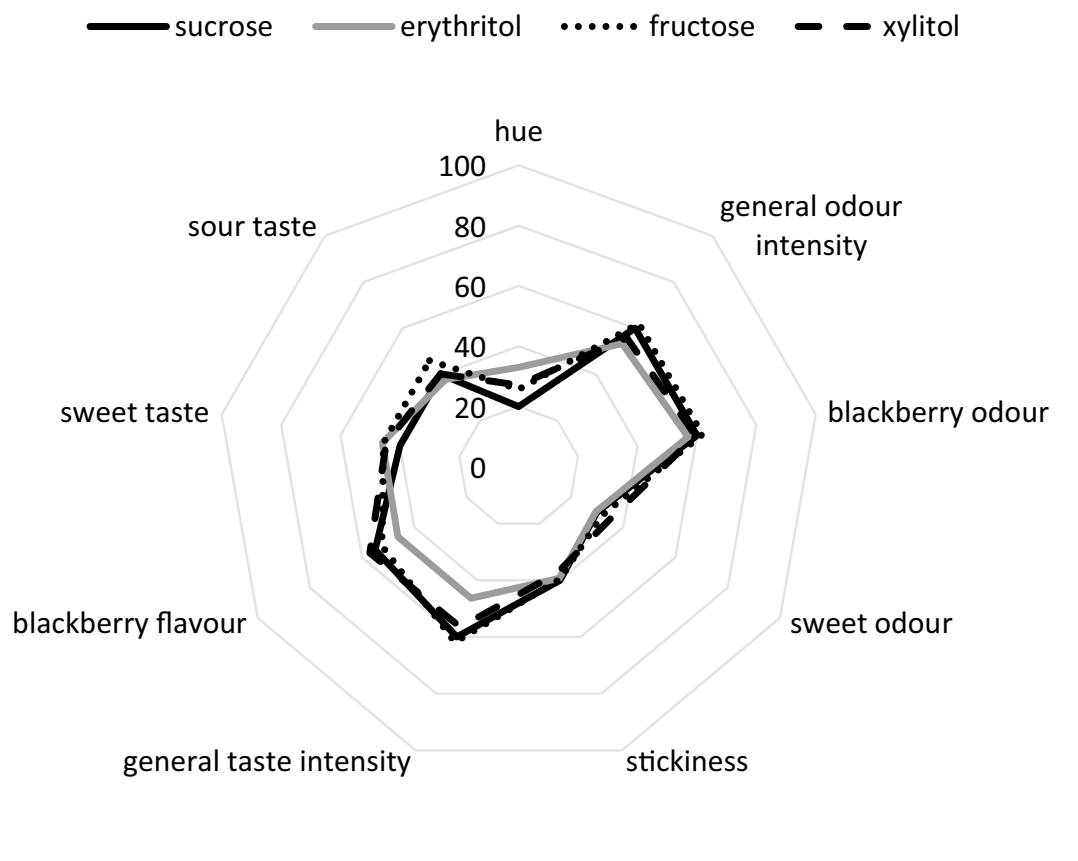

b

(metal oxide semiconductor field-effect transistor) sensors, 12 MOS (metal oxide semiconductor) sensors, and a sensor for relative humidity measurements. Ambient air was used as a reference gas for the sensors, which was filtered through a silica gel column and a combined moisture/hydrocarbon filter. The gas flow rate of the dynamic sampling was set to $50 \mathrm{ml} / \mathrm{min}$. The electronic nose measurement sequence started with sample equilibration at $30^{\circ} \mathrm{C}$ for $15 \mathrm{~min}$. Then reference air was pumped over the sensor surfaces for $10 \mathrm{~s}$ (baseline) followed by the infusion headspace for $20 \mathrm{~s}$ (sampling time) while the sensor signals were recorded. After sample analysis, the recovery phase of the sensors was set to $260 \mathrm{~s}$ including the flush time of the gas lines (60 s) with filtered air prior to the next sample injection to allow the 
re-establishment of the instrument baseline. The total cycle time per sample was $300 \mathrm{~s}$. Each sample was measured 3 times and the results of nine measurements from three replicate samples were used for the statistical analysis.

\section{Identification of phenolic compounds by LC-MS}

Ultra-high performance liquid chromatography and electrospray ionisation triple quadrupole tandem mass spectrometry (UHPLC-ESI-MS/MS) was used to monitor the following 12 polyphenols: caffeic acid, catechin, chlorogenic acid (5-caffeoyl-quinic acid, 5-CQA), cyanidin-glucoside (kuromanin), cyanidin-rutinoside (keracyanin), epicatechin, ferulic acid, neochlorogenic acid (3-caffeoyl-quinic acid, 3-CQA), $p$-coumaric acid, quercetin, quercetin-3-Oglucoside, quercetin-3-O-rutinoside (rutin). Quinic acid in 3-CQA and 5-CQA was considered as 1L-(-)-quinic acid $3 \mathrm{R}, 5 \mathrm{R}-(1 \alpha, 3 \alpha, 4 \alpha, 5 \beta)$ [26] and its caffeoyl derivatives were assigned using the IUPAC 1976 numbering of cyclitols [27].

Compounds were separated on a Phenomenex Kinetex EVO C18 $100 \times 2.1 \mathrm{~mm}, 100 \mathrm{~A}, 2.6 \mu \mathrm{m} \mathrm{C} 18$ column (plus similar pre-column) with gradient elution using high purity water containing $0.1 \%$ formic acid (mobile phase $\mathrm{A}$ ) and UHPLC-MS grade acetonitrile (mobile phase B). Flow rate was $0.5 \mathrm{~mL} / \mathrm{min}$ and the injection volume was $10 \mu \mathrm{L}$. Gradient profile was as follows: 0 min 5\% B; 4 min 60\% B; $4.1 \mathrm{~min}$ $100 \%$ B; 5.1 min 100\% B and 1 min post time. Column was kept at $30{ }^{\circ} \mathrm{C}$. Analysis was carried out in $6.1 \mathrm{~min}$ on an Agilent Infinity II UHPLC coupled to an Ultivo ESI QQQ MS/ MS system. Mass spectrometric detection was performed in positive ion mode for kuromanin and keracyanin and in negative ion mode for the remaining ten compounds, applying the dynamic multiple reaction (dMRM) scanning mode. Method was previously optimised with reference standards for each analyte. Matrix-matched calibration was used for quantification and sample extract $(0.5 \mathrm{~g}-20 \mathrm{~mL})$ was fivefold diluted in mobile phase ' $A$ ' and filtered through a $0.22 \mu \mathrm{m}$ PTFE syringe filter before injection.

\section{Statistical evaluation}

At the first step, results were analysed using descriptive statistics; average and standard deviation were calculated after outlier detection. Sensory data were screened for outliers using the z-score method. Outlier data was substituted with the group averages. Significant difference within different factors such as the storage time and sweetening agent were performed using two-way repeated-measures ANOVA. Due to the number of the observations this test was performed only in the case of the $L^{*} a^{*} b^{*}, \Delta \mathrm{E}$, total polyphenol content, ABTS antioxidant capacity and the results of the sensory profile analysis. It was not possible to evaluate the interaction between the two factors as the number of degrees of freedom available for the calculations was too low. The test also did not provide sufficient results for the monomeric anthocyanins and individual phenolic compounds due to the lower number of observations and thus the eligible degrees of freedom. However, the assumptions of the test were analysed, i.e. elimination of outliers, normality and Mauchly's sphericity test. In the case of significant Mauchly's test of sphericity, the results were corrected using the Greenhouse-Geisser test (when $p<0.75$ ). The pairwise comparisons were done using the Bonferroni adjustment at $p<0.05$ significance level [28].

In the case of the electronic tongue and nose results, outliers were identified based on the exploratory data evaluation (principal component analysis, PCA) and omitted before further data evaluation. As raw data pre-treatment, drift correction was applied in the case of ET to decrease the impact of the sensor drift during the different days [29]. Linear discriminant analysis (LDA) was applied to build models for the classification of groups according to the sweetening agents based on the results of ET and EN validated by three-fold cross-validation. Microsoft Excel 365 was used for the descriptive statistics, while R-project 3.5.2 software was used for processing the data of the EN and ET. Profile analysis results were evaluated using ProfiSens v. 2012 software [24]. The two-way repeated-measures ANOVA test was performed in IBM SPSS statistics software (Amonk, New York, USA). Sensory analysis data was evaluated using multiple factor analysis (MFA) to conduct a joint analysis of the five sensory sessions. MFA conducts individual PCAs on each of the data matrix and then merges them; hence enabling the researcher to analyse and visualize multiple data matrices as a whole. MFA was run using the XL-Stat software (Addinsoft, Long Island, NY, USA) [30].

\section{Results and discussion}

\section{Total soluble solids, total polyphenol content and antioxidant activity}

Refractometry did not show a clear increment of the Brix values (Table 1), therefore, we could assume that there were no substantial losses due to evaporation, thus variations of the measured physicochemical and sensory parameters reflect the changes that occurred as a result of the chemical processes related to storage.

Global variation in total polyphenol content was followed by Folin-Ciocalteu assay during the whole storage period (Table 1). After an initial drop in the first 3 months (from 6.55 to $5.73 \mathrm{mg} \mathrm{GAE} / \mathrm{g}$ for sucrose-, from 7.91 to $6.85 \mathrm{mg} \mathrm{GAE} / \mathrm{g}$ for fructose-, from 7.50 to $5.80 \mathrm{mg} \mathrm{GAE} / \mathrm{g}$ for xylitol- and from 6.85 to $6.13 \mathrm{mg} \mathrm{GAE} / \mathrm{g}$ for erythritol-containing jams), an increase was observed for all the 
Table 1 Total polyphenol content, ABTS antioxidant capacity, total monomeric anthocyanin content and $\mathrm{L}^{*}, \mathrm{a}^{*}, \mathrm{~b}^{*}$ and $\Delta \mathrm{E}$ colour values of jams

\begin{tabular}{|c|c|c|c|c|c|c|c|c|}
\hline $\begin{array}{l}\text { Sweet- } \\
\text { ener/ } \\
\text { month }\end{array}$ & $\begin{array}{l}\text { Total soluble } \\
\text { solids (Brix, } \\
\% \text { ) }\end{array}$ & $\begin{array}{l}\text { Total polyphe- } \\
\text { nol content (mg } \\
\text { GAE/g jam) }\end{array}$ & $\begin{array}{l}\text { ABTS antioxidant } \\
\text { capacity }(\mu \mathrm{mol} \mathrm{TE} \\
\text { / g jam) }\end{array}$ & $\begin{array}{l}\text { Total monomeric } \\
\text { anthocyanins (mg } \\
\text { cyanidin-3-gluco- } \\
\text { side equivalents } \\
/ 100 \mathrm{~g} \text { jam) }\end{array}$ & $L^{*}$ & $a^{*}$ & $b^{*}$ & $\Delta \mathrm{E}$ \\
\hline \multicolumn{9}{|l|}{ Sucrose } \\
\hline 0 & $36.25 \pm 0.17$ & $6.55 \pm 0.35$ & $82.59 \pm 3.44$ & $74.03 \pm 3.56$ & $29.21 \pm 0.14$ & $4.02 \pm 0.05$ & $-0.46 \pm 0.02$ & - \\
\hline 1 & $36.60 \pm 0.12$ & $6.09 \pm 0.22$ & $82.17 \pm 2.88$ & $59.14 \pm 5.19$ & $29.71 \pm 0.34$ & $3.78 \pm 0.13$ & $-0.55 \pm 0.06$ & $0.64 \pm 0.29$ \\
\hline 3 & $36.62 \pm 0.13$ & $5.73 \pm 0.32$ & $79.28 \pm 5.64$ & $35.54 \pm 1.26$ & $29.83 \pm 0.49$ & $3.65 \pm 0.12$ & $-0.40 \pm 0.05$ & $0.77 \pm 0.38$ \\
\hline 6 & $37.28 \pm 0.36$ & $6.82 \pm 0.13$ & $69.89 \pm 4.24$ & $23.18 \pm 1.98$ & $29.41 \pm 0.35$ & $3.50 \pm 0.08$ & $-0.51 \pm 0.02$ & $0.60 \pm 0.11$ \\
\hline 9 & $37.52 \pm 0.50$ & $6.72 \pm 0.13$ & $77.53 \pm 5.70$ & $16.17 \pm 2.85$ & $29.27 \pm 0.40$ & $3.48 \pm 0.05$ & $-0.52 \pm 0.02$ & $0.63 \pm 0.17$ \\
\hline \multicolumn{9}{|c|}{ Fructose } \\
\hline 0 & $36.10 \pm 0.10$ & $7.91 \pm 0.37$ & $84.78 \pm 6.01$ & $57.76 \pm 3.89$ & $29.17 \pm 0.14$ & $4.40 \pm 0.05$ & $-0.36 \pm 0.02$ & - \\
\hline 1 & $35.18 \pm 0.19$ & $7.25 \pm 0.17$ & $79.64 \pm 4.25$ & $35.07 \pm 3.51$ & $29.34 \pm 0.31$ & $4.18 \pm 0.07$ & $-0.38 \pm 0.03$ & $0.44 \pm 0.23$ \\
\hline 3 & $33.98 \pm 0.28$ & $6.85 \pm 0.22$ & $77.59 \pm 2.95$ & $19.23 \pm 1.34$ & $29.83 \pm 0.38$ & $4.04 \pm 0.15$ & $-0.31 \pm 0.05$ & $1.28 \pm 0.37$ \\
\hline 6 & $33.92 \pm 0.13$ & $7.60 \pm 0.12$ & $70.45 \pm 1.32$ & $15.03 \pm 1.45$ & $28.90 \pm 0.30$ & $3.89 \pm 0.16$ & $-038 \pm 0.05$ & $0.62 \pm 0.19$ \\
\hline 9 & $34.84 \pm 0.23$ & $8.15 \pm 0.24$ & $66.81 \pm 3.09$ & $10.13 \pm 0.29$ & $29.62 \pm 0.49$ & $3.88 \pm 0.11$ & $-0.32 \pm 0.08$ & $0.54 \pm 0.14$ \\
\hline \multicolumn{9}{|l|}{ Xylitol } \\
\hline 0 & $34.06 \pm 0.36$ & $7.50 \pm 0.26$ & $87.09 \pm 4.61$ & $77.62 \pm 1.25$ & $29.14 \pm 0.12$ & $4.93 \pm 0.12$ & $-0.15 \pm 0.01$ & - \\
\hline 1 & $34.06 \pm 0.11$ & $6.78 \pm 0.18$ & $84.90 \pm 2.57$ & $50.07 \pm 0.88$ & $29.55 \pm 0.34$ & $4.62 \pm 0.12$ & $-0.28 \pm 0.04$ & $0.73 \pm 0.27$ \\
\hline 3 & $36.28 \pm 0.33$ & $5.80 \pm 0.26$ & $71.98 \pm 4.06$ & $32.42 \pm 0.82$ & $29.37 \pm 0.22$ & $4.43 \pm 0.07$ & $-0.37 \pm 0.01$ & $0.65 \pm 0.28$ \\
\hline 6 & $35.43 \pm 0.25$ & $7.04 \pm 0.05$ & $70.15 \pm 1.53$ & $22.15 \pm 2.19$ & $29.80 \pm 0.40$ & $4.04 \pm 0.02$ & $-0.43 \pm 0.01$ & $1.18 \pm 0.35$ \\
\hline 9 & $36.30 \pm 0.10$ & $7.21 \pm 0.19$ & $70.70 \pm 2.20$ & $16.11 \pm 1.01$ & $29.12 \pm 0.07$ & $3.96 \pm 0.03$ & $-0.40 \pm 0.01$ & $0.99 \pm 0.39$ \\
\hline \multicolumn{9}{|c|}{ Erythritol } \\
\hline 0 & $40.60 \pm 0.14$ & $6.85 \pm 0.26$ & $79.10 \pm 6.24$ & $65.74 \pm 3.23$ & $29.16 \pm 0.20$ & $5.94 \pm 0.14$ & $-0.37 \pm 0.01$ & - \\
\hline 1 & $40.26 \pm 0.42$ & $6.75 \pm 0.36$ & $75.51 \pm 9.02$ & $52.85 \pm 2.76$ & $29.63 \pm 0.57$ & $5.75 \pm 0.04$ & $-0.42 \pm 0.03$ & $0.44 \pm 0.32$ \\
\hline 3 & $40.55 \pm 0.13$ & $6.13 \pm 0.13$ & $77.82 \pm 7.43$ & $31.17 \pm 1.84$ & $29.50 \pm 0.26$ & $5.72 \pm 0.03$ & $-0.38 \pm 0.08$ & $0.52 \pm 0.32$ \\
\hline 6 & $40.78 \pm 0.15$ & $7.08 \pm 0.10$ & $76.98 \pm 8.73$ & $19.29 \pm 1.17$ & $29.53 \pm 0.19$ & $5.16 \pm 0.04$ & $-0.44 \pm 0.03$ & $0.94 \pm 0.28$ \\
\hline 9 & $40.46 \pm 0.17$ & $6.64 \pm 0.36$ & $79.24 \pm 5.37$ & $14.25 \pm 0.84$ & $28.96 \pm 0.17$ & $5.05 \pm 0.03$ & $-0.36 \pm 0.01$ & $0.95 \pm 0.08$ \\
\hline
\end{tabular}

Mean \pm standard deviation

sweeteners used, followed by a gradual decrease. Thus, in the 9th month the total polyphenol content measured by Folin assay ended up in values that were even higher than the initial ones $(6.72 \mathrm{mg} \mathrm{GAE} / \mathrm{g}$ for sucrose- and $8.15 \mathrm{mg}$ GAE/g for fructose-based jams) or close to the initial values $(7.21 \mathrm{mg} \mathrm{GAE} / \mathrm{g}$ for xylitol- and $6.64 \mathrm{mg} \mathrm{GAE} / \mathrm{g}$ for erythritol-sweetened jams). Results of the repeated measures ANOVA test showed that the sweetening agent $(p<0.001)$ and time $(<0.001)$ had a significant effect on the total polyphenol content of the jams. Significantly lower values were obtained for jams containing sucrose compared to jams containing fructose and xylitol. Fructose-based samples showed also significantly higher values compared to erythritol- and xylitol-based jams. Analysis of the effect of storage time showed that significantly lower polyphenol content was obtained for samples in the $3^{\text {rd }}$ month compared to all the other sampling points, while 1-month old jams showed also significantly lower phenolic content than 6and 9-month-old samples. However, these changes did not reflect only the evolution of the original polyphenol content of the jams, where a decay was registered for almost all the compounds (especially the anthocyanins) monitored by LC-MS. The chemistry behind the differences observed by the two methods involves parallel processes: in addition to the degradation of the original phenolic compounds, the total polyphenol content measured by the Folin method covers other transformations as well, especially those resulting from the Maillard reaction, where new antioxidants are formed. Therefore, Folin assay will not reflect properly the overall changes of the endogenous phenolic compounds in jams with different sweeteners.

For most of the jams, polyphenol changes were not reflected in the decay of antioxidant capacity; Pearson correlation coefficients revealed weak correlations, which are generally not significant: sucrose: $r=-0.013, p=0.953$, fructose: $r=-0.405, p=0.049$ (significant at 0.05 level, 2-tailed), xylitol: $r=0.312, p=0.129$, erythritol: $r=-0.198, p=0365$. ABTS values showed a generally a non-linear decreasing 
trend with some exceptions (Table 1). An increase of $112 \%$ was detected for sucrose from month 6 to month 9 , which was not observed for the rest of the sweeteners. Results of the repeated measures ANOVA test of ABTS antioxidant capacity showed that it was not affected significantly by the sweetening agent $(p=0.158)$, while storage time had a significant effect on the results $(p<0.001)$. Samples stored for 6 and 9 months showed significantly lower ABTS values compared to the freshly prepared jam samples and samples stored for 1 month, while jams stored for 3 months showed significantly higher antioxidant capacities compared to the 6-month-old samples, and significantly lower compared to 1-month old samples.

A number of papers report decay of polyphenols (specifically anthocyanins) during thermal processing of fruits and vegetables [10,31], while others found an inconsistent trend in the variation of these substances. Although a decrease in the antioxidant potential is typical for short heat treatments, a retrieval of these properties has been reported during prolonged heat treatment and/or storage. In our case, the observed oscillation in total polyphenol content and ABTS antioxidant activity during 9 months of storage were in line with the results obtained by many others for various products, including fruit liqueurs and diet jams [10, 32]. Many studies found that phenolic antioxidants do not follow a specific reaction order. Even an increase of phenolic compounds was observed in the case of several processed fruit products, while native phenolics were degraded. The apparently unpredictable fluctuation of these values was explained by multiple mechanisms, including caramelising, Strecker degradation and Maillard reaction, degradation of phenolics with higher molecular mass to smaller phenolic molecules with potential antioxidant activity and various transformations of anthocyanins. Sugar-derived products formed in the advanced stages of the Maillard reaction, specifically furfural and hydroxylmethylfurfural, which were not detected in sugar-free jams, are known to accelerate anthocyanin degradation, leading to the formation of anthocyanin-procyanidin polymers and inducing a decay in global antioxidant capacity [33] Finally, in the last stage of the Maillard reaction brown-coloured melanoidins with high molecular weights are formed that possess antioxidant activity. On the other hand, some of the reaction products formed in the early stages of the Maillard reaction can act as pro-oxidants, thus the whole Maillard process contributes to initial decay and later an increase in antioxidant activity [10], which was in line with our observations. Antioxidant compounds depletion in thermally treated fruits is also attributed to consumption of ascorbic acid and polyphenols as reactants in the Maillard reaction [10], ascorbic acid being also consumed in the caramelization reaction between reducing sugars and ascorbic acid, which can partly explain the observed incoherence between changes in polyphenol and antioxidant activity of our blackberry preparations. It is also known that fructose, as a monosaccharide, has a faster rate of Maillard reaction than sucrose, which contributes to this reaction only after its hydrolysis. This can account for the differences in antioxidant properties of sucrose- and fructose-containing jams during storage, especially the rise of antioxidant capacity from month 6 to month 9 [34]. Finally, transformations of anthocyanins and other components during storage lead to polymerization and formation of new molecules that can react with Folin-Ciocalteu reagent, thus increasing the apparent polyphenol content. Hence, our results confirmed that the Folin-Ciocalteu method is not appropriate for observing polyphenol changes during storage and it should be definitely completed by quantitative monitoring of the native individual phenolics to follow their evolution.

Additionally, the inconsistent trend in antioxidant activity change can be attributed to various reasons, including the hydrolysis of the flavonoid glycosides, delivering an additional -OH moiety that can react with the ABTS cation radical [32]. Moreover, the interaction of the phenolic compounds or their oxidized form with the sugar molecules and the consequent formation of the reduced form of phenolic compounds that can interact with ABTS radicals [35] orto a lesser extent-the presence of non-polyphenol antioxidants can also contribute to the observed lack of correlation between polyphenol content and ABTS radical scavenging activity obtained in our study. Other authors attribute the phenomenon to other factors, such as increased antioxidant power of polyphenols at an intermediate state of oxidation, increase in reducing sugar and formation of Maillard products, known to show a high antioxidant activity, which is often exerted in mechanisms similar to that of the ABTS assay [36]. As regards the impact of the sweeteners used, no significant differences were reported in the antioxidant activity (including ABTS radical scavenging activity) of aronia jams prepared with sucrose, xylitol and erythritol, whereas-in accordance with our findings-significant differences in total polyphenol content were found, nevertheless, these authors obtained the highest TPC values for xylitol [37].

\section{Total monomeric anthocyanin content}

Anthocyanin degradation, one of the main processes affecting total phenolics content is reported by many authors in berry products and is partly attributed to indirect oxidation by the phenolic quinones generated by the endogenous polyphenol oxidase and peroxidase enzymes [10]. Losses of monomeric anthocyanins in berry preserves take place via both anthocyanin degradation and polymerization, even before heat treatment (by enzymatic polymerization) and during storage. Nevertheless, these polymeric compounds 
are supposed to contribute to the overall antioxidant capacity, and compensate degradation losses, even though their in vivo activity may be completely different. They are also reported to be resistant to colour changes, regardless of $\mathrm{pH}$ $[7,10]$.

Deterioration of anthocyanins was registered during the whole storage period for all the sweeteners. Anthocyanin content of freshly prepared sucrose $(74.03 \pm 3.56 \mathrm{mg}$ cyanidin-3-glucoside equivalents/100 g) and xylitol $(77.62 \pm 1.25 \mathrm{mg}$ cyanidin-3-glucoside equivalents $/ 100 \mathrm{~g})$ jams was higher than for jams with fructose $(57.76 \pm 3.89 \mathrm{mg}$ cyanidin-3-glucoside equivalents/100 g) and erythritol $(65.74 \pm 3.23 \mathrm{mg}$ cyanidin-3-glucoside equivalents $/ 100 \mathrm{~g})$, but these differences were partly compensated during storage; however, by the end of the 9th month the fructose-containing jam showed a lower monomeric anthocyanin content than the other samples.

Degradation of anthocyanins followed first-order kinetics, as described in previous reports on processed blackberry products $[8,10]$. The reaction rate constants $[k=-\ln (\mathrm{A} /$ $\mathrm{A} 0 * t)]$ and the half-life values $\left[t_{1 / 2}=\ln (2) / k\right]$ of the degradation showed that the reaction was the slowest in the case of xylitol $\left(k=0.0046 \mathrm{day}^{-1}, t_{1 / 2}=150.68\right.$ days $)$, followed by sucrose $\left(k=0.0051\right.$ day $^{-1}, t_{1 / 2}=135.91$ days $)$ and erythritol ( $k=0.0053 \mathrm{day}^{-1}, t_{1 / 2}=130.78$ days $)$, while decomposition was the fastest in the fructose-containing preparation $\left(k=0.0055 \mathrm{day}^{-1}, t_{1 / 2}=126.03\right.$ days). In line with our observations, in strawberry jams fructose is reported to have a more pronounced degradation effect on anthocyanins compared to glucose, sucrose and maltose [38]. This can be attributed to the enhanced rate of the Maillard reaction in the presence of fructose and thus to the formation of furfural and hydroxylmethylfurfural, shown to have a destructive effect on anthocyanins, as mentioned earlier.

Compared to fructose, erythritol and xylitol performed better, but only xylitol was superior to sucrose in terms of a lower degradation rate of anthocyanins. In a study, sour cherry purees prepared with sugar alcohols, erythritol and xylitol also showed protective effects on anthocyanins after 6-months storage and both were superior to sucrose when preparations were stored cooled, but not when storage took place at a higher temperature [39]. In another paper, pre-process sucrose addition resulted in colour improvement. This was attributed to a stabilizing effect of sugar on monomeric anthocyanins by decreasing the rate of anthocyanin degradation. This stabilizing effect is thought to be a consequence of a drop in water activity [32].

\section{Polyphenol profile}

Changes in phenolic composition during storage were monitored by LC-MS (Fig. 2). The individual compounds and their evolution during the investigation period are shown in (Table 2).

Most of the polyphenols reported in fresh blackberries (Rubus fruticosus L.) were found in the jams prepared with either sugars or sugar alcohols The main polyphenols detected were flavonoids: anthocyanins (cyanidin-3-Oglucoside/kuromanin and cyanidin-rutinoside/keracyanin), flavan-3-ols (epicatechin, catechin), flavonols (quercetin, quercetin-glucoside and quercetin-3-O-rutinoside/rutin). This is in line with the values reported for blackberries, widely known for their high phenolic content. The most important polyphenols in whole fruit are anthocyanins, from which cyanidin-3-glucoside was the dominant one in blackberry jams (between 0.19 and $21.44 \mathrm{mg} / 100 \mathrm{~g}$ ), whereas cyanidin-rutinoside was detected only in trace amounts [18]. The main phenolic acids and their derivatives detected in our blackberry jams were chlorogenic acid (5-CQA), neochlorogenic acid (3-CQA), $p$-coumaric acid and ferulic acid. These findings are in accordance with Belitz et al., mentioning hydroxycinnamic and hydroxybenzoic acid derivatives as main non-flavonoids in blackberries: caffeoylquinic acids (chlorogenic and neochlorogenic acid) (45-53 mg/kg), 4-hydroxybenzoic acid ( $p$-coumaric acid) $(10-16 \mathrm{mg} / \mathrm{kg})$, protocatechuic acid $(68-189 \mathrm{mg} / \mathrm{kg})$ and gallic acid (8-67 mg/kg) [13]. Their decomposition during storage reflected the main trends observed in the changes of monomeric anthocyanins, fructose being the sweetener that resulted in the quickest degradation during the whole period. Xylitol generally showed slightly better protection potential than erythritol, and both were superior to sucrose in many cases. Thus, sugar alcohols, especially xylitol, seemed to be the most suitable choice in terms of conservation of fruitbased polyphenols in the jams prepared. This was in accordance with the colour changes of these preparations observed on the red-green scale.

A gradual decomposition of the main anthocyanin, cyanidin-3-glucoside was observed for all the sweeteners: its amount in the 9th month was approximately similar in sucrose- $(6.1 \pm 0.5 \mathrm{mg} / 100 \mathrm{~g})$, xylitol- $(7.3 \pm 0.1 \mathrm{mg} / 100 \mathrm{~g})$ and erythritol- $(5.7 \pm 1.3 \mathrm{mg} / 100 \mathrm{~g})$ containing jams (around $25-30 \%$ of the original amounts: $31.3 \pm 3.5,26.6 \pm 5.2$ and $28.8 \pm 0.5 \mathrm{mg} / 100 \mathrm{~g}$ for sucrose, xylitol and erythritol, respectively), but it was drastically reduced in fructosebased preparation $(2.5 \pm 0.3 \mathrm{mg} / 100 \mathrm{~g}$, i.e., around $11 \%$ of the original amount of $23.3 \pm 3.1 \mathrm{mg} / 100 \mathrm{~g}$ ).

The reaction rate constants $[k=-\ln (\mathrm{A} / \mathrm{A} 0 * t)]$ and the half-life values $\left(t_{1 / 2}=\ln (2) / \mathrm{k}\right)$ derived from cyanidin-3-glucoside data were in accordance with the ones derived from the total monomeric anthocyanin measurements regarding fructose and xylitol; the two sweeteners resulting in the quickest and the slowest degradation of anthocyanins, respectively. Xylitol provided the slowest degradation ( $k=0.0041$ day $^{-1}, t_{1 / 2}=169.06$ days $)$ and the decomposition 
Fig. 2 UHPLC-ESI-MS/MS chromatogram of the freshlyprepared sucrose-containing sample. Chromatograms are showing the measured quantitative MRM transitions, indicated in each chromatogram next to the compound name

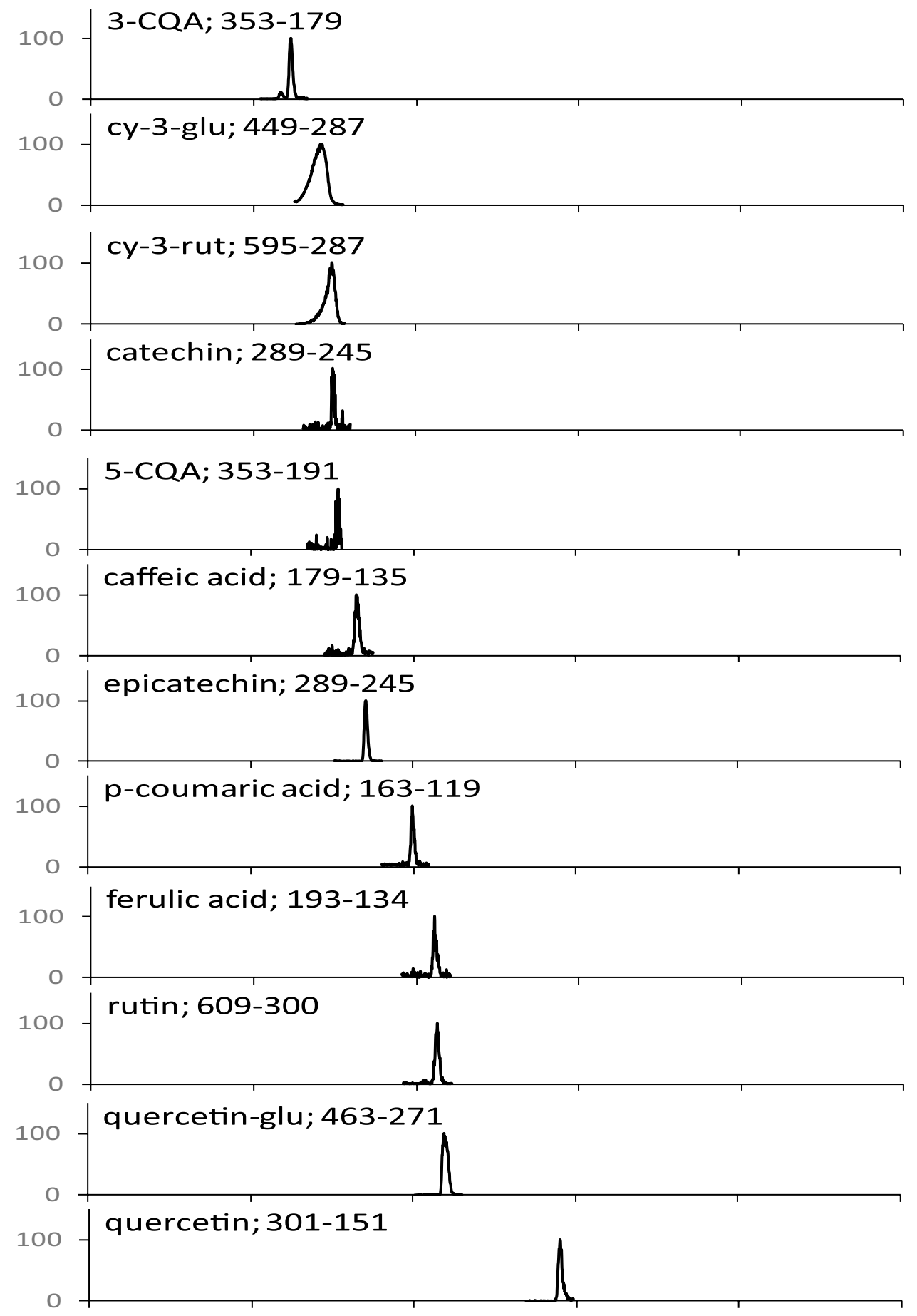

was the quickest in the fructose-containing preparation ( $k=0.0075 \mathrm{day}^{-1}, t_{1 / 2}=92.42$ days $)$. However, in contrary to total monomeric anthocyianin-based results, the order of erythritol ( $k=0.0056$ day $^{-1}, t_{1 / 2}=123.78$ days $)$ and sucrose ( $k=0.0057$ day $^{-1}, t_{1 / 2}=121.61$ days) was swapped.

Cyanidin-3-rutoside decomposed in a very similar manner to cyanidin-3-glucoside, whereas quercetin glycosides seemed to be less sensitive to storage. Regarding flavan3-ols, epicatechin was far more sensitive to storage than catechin, and the former diminished most substantially in the fructose-based preparation, where its final amount was approximately half or even less $(1.3 \pm 0.0 \mathrm{mg} / 100 \mathrm{~g}) \mathrm{com}-$ pared to the other jams $(2.6 \pm 0.0 \mathrm{mg} / 100 \mathrm{~g}$ for sucrose, $3.7 \pm 0.1 \mathrm{mg} / 100 \mathrm{~g}$ for xylitol, $2.3 \pm 0.0 \mathrm{mg} / 100 \mathrm{~g}$ for erythritol). The observed increase in catechin content might be attributed to its formation by gradual epimerization of epicatechin. Slight increase of some compounds, like phenolic acids ( $p$-coumaric acid, caffeic acid) and a flavonoid 


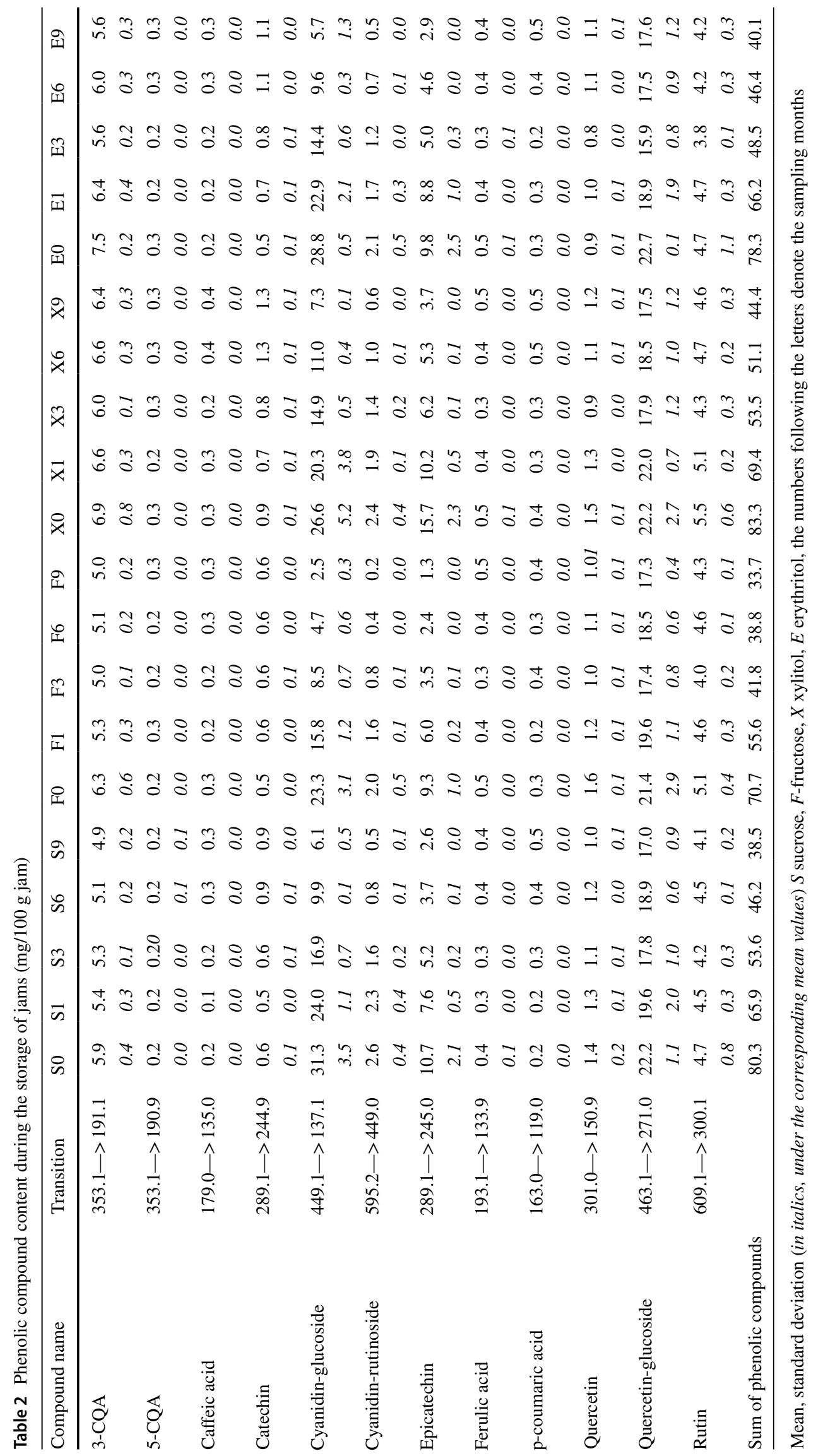


aglycone (quercetin, in case of erythritol-based jams) was noticed during storage. This can be explained either by matrix decomposition processes, that may result in the liberalisation of smaller free phenolic acids from more complex native molecules, e.g., $p$-coumaric acid from chlorogenic acids, or the release of free flavonoid aglycone forms from the corresponding glycosides (e.g., quercetin from rutin).

\section{Colour changes}

Colour changes were monitored on the $L^{*}, a^{*}$ and $b^{*}$ scales during storage time, colour differences $(\Delta \mathrm{E})$ were also calculated (Table 1). Lightness of the jams showed an increase in the first three months and a decrease until the end of the storage period in case of sugars, whereas these trends ran almost inversely for sugar alcohol-containing jams, having ended up in very similar values. Results of the repeated measures ANOVA test of $\mathrm{L}^{*}$ values showed that the sweetening agent had no significant effect on the lightness of the jams, while the storage period produced such an effect $(p=0.03)$. The pairwise comparison showed no significantly different groups using the Bonferroni adjustment at $p<0.05$, however, the least significant difference test (that is equivalent to no adjustment) showed $(p=0.021)$ that the samples stored for 9 months were significantly darker than samples stored for 1 and 3 months. This is somewhat controversial to the observed increase of lightness of various strawberry jams [39] or cherry jams, as observed by Rababah et al. (2014) [41]. Mamede et al. (2013) found that sucrose-containing jams made of umbu-caja were darker than those prepared with xylitol [40], which was not the case for our blackberry jams.

Results of the repeated measures ANOVA test of $a^{*}$ values showed that both sweetening agent and storage time had a significant effect on the red hue of the samples at $p<0.001$ significant level, according to the within-subject effect tests. In the case of the effect of sweetening agents, significant differences were found among all of the groups, the decreasing order being: erythritol, xylitol, fructose, sucrose. The effect of the storage time showed that samples stored for 6 and 9 months showed significantly lower $a^{*}$ values than the others and samples stored for 9 months obtained also significantly lower $\mathrm{a}^{*}$ compared to the 6 months stored samples, i.e. the red hue of the samples was significantly reduced from month 6 . On the other hand, 1-month old samples, showed a significant decrease in redness compared to the fresh samples, while these differences were statistically not relevant for 3-month old samples.

Changes on the yellow-blue scale are inconsistent, as a result, no marked decrease was observed in the global $b^{*}$ values at the end of the observation period, the initial differences having been equalized. Results of the repeated measures ANOVA test of $b^{*}$ showed a significant effect of the sweetening agent on the bluishness of the samples $(p<0.001)$, while storage time did not affect significantly the results $(p=0.094)$. Significant difference was found between erythritol sweetened jams compared to the sucrose-, fructose- and xylitol-sweetened jams: erythritol-sweetened jams were less bluish than the other three jams.

$\Delta \mathrm{E}$ values showed that the global colour differences compared to the freshly prepared jams are higher at the end of the storage period for sugar alcohol-containing jams $(0.99 \pm 0.39$ for xylitol and $0.95 \pm 0.08$ for erythritol). These differences are almost double compared to sugar-containing jams $(0.63 \pm 0.17$ for sucrose and $0.54 \pm 0.14$ for fructose $)$, however, repeated measures ANOVA revealed no significant differences determined by either sweetener or time. It should be noted that $\Delta \mathrm{E}$ values are not following a continuously increasing trend, thus reflecting the fluctuating changes of $L^{*}, a^{*}$ and $b^{*}$ values. This way, the maximum $\Delta \mathrm{E}$ values are not necessarily reached by the end of the storage period. Nonetheless, in all the cases these values denote colour differences that are not perceived by humans $(\Delta \mathrm{E}<1)$ or, in the case of xylitol-based jams, perceived only by experienced observers $(1<\Delta \mathrm{E}<2)[41]$.

It was reported that sucrose-containing aronia jams showed the lowest $L^{*}, a^{*}$ and $b^{*}$ values, followed by xylitol and erythritol [37] - this was confirmed in this study for $a^{*}$ and $b^{*}$ values. Some other authors also found that the intensity of red hue was higher in light cherry jams compared to those with higher sucrose content, both at preparation and after storage [42]. The positive effect of xylitol on colour reported for strawberry jams [43] and the protecting effect of both xylitol and erythritol on the colour of sour cherry purees [39] was confirmed in our experiments. Erythritol-containing jams were significantly higher in red hue than all the other jams, suggesting that total concentration of monomeric anthocyanin species are not the only determinant in colour expression. This phenomenon was also reported by Garcia-Viguera et al. (1997) [15] and others [10] and was explained by the co-pigmentation: phenolic acids, flavonols and flavan-3-ols are known to interact with anthocyanins, producing an enhancement of colour intensity. Ifie et al. found that hydroxycinnamic acids are involved in the formation of new stable anthocyanin-derived pigments through condensation reactions with anthocyanins which may account for maintaining colour intensity [44]. Comparing the concentration of the phenolic compounds mentioned above in sucrose- and erythritol-containing jams, it was stated that all of them (i.e., quercetin derivatives: rutin, quercetin glucoside, quercetin, flavan-3-ols: catechin, epicatechin and all the phenolic acids (5-CQA, 3-CQA, $p$-coumaric acid, ferulic acid)) were present in higher amounts in the jams containing erythritol than in the jams containing sucrose, contributing thus to colour compensation. Nevertheless, a strong correlation between $a^{*}$ (red) values and 
total monomeric anthocyanin content was observed for all the sweeteners (Pearson correlation coefficients at $p=0.05$ are: sucrose: 0.98 , fructose: 0.99 , xylitol: 0.97 , erythritol: 0.92).

\section{Sensory analysis}

In addition to colour, changes in the phenolic profile are also linked to other sensory attributes of the products, their alteration may be accompanied by changes in flavour and aroma as well. There are many papers reporting a comparison of sensory properties of preserved products containing sugar or sugar alcohols, especially xylitol. This latter is found to show similar or even superior properties in various food products when compared to sucrose. Sensory properties of umbu-caja jams made with sucrose were close to the ones made with xylitol, no significant differences were obtained for appearance, flavour and texture [40]. During the comparative sensory evaluation of jams containing sucrose, xylitol or erythritol, the xylitol-containing jam reached the best results in terms of taste, flavour and overall acceptance [35]. Xylitol showed a good performance with other fruit-containing products as well, reaching higher scores for fruity notes than sucrose [45]. The use of xylitol led to a good sensory acceptance even at high concentrations [46] being thus generally considered a good choice as a sugar substitute in jams.

During the 9-months storage period, the sensory properties of our blackberry jams were comparatively evaluated by the panel. Sensory profile of the samples at the beginning and at the end of the period investigated are shown in Fig. 1.

According to the two-way repeated-measures ANOVA analysis (Table 3 ), the sweetening agents had a significant effect (significance level $p<0.01$ ) on all the investigated sensory parameters. Erythritol-sweetened jams were significantly more reddish (higher hue values) compared to the other groups, while sucrose-sweetened jams were characterized by significantly lower-rated hues, i.e. hues closer to black. A remarkable consistency was obtained between the evaluation of the panel for the hue (black-dark red scale) and the results obtained by colorimetry for $a^{*}$ values: erythritol was found to show the most intense red colour, which is reportedly one of the most important attributes, significantly determining consumer preference [47]. On the other hand,

Table 3 Significant differences between physicochemical and sensory attributes as calculated by repeated measures ANOVA regarding sweetening agent and storage time

\begin{tabular}{|c|c|c|c|c|c|c|c|c|c|}
\hline Parameter & Sucrose & Fructose & Xylitol & Erythritol & Month 0 & Month 1 & Month 3 & Month 6 & Month 9 \\
\hline TPC & $6.38 \pm 0.48^{\mathrm{A}}$ & $7.55 \pm 0.52^{\mathrm{C}}$ & $6.86 \pm 0.62^{\mathrm{B}}$ & $6.69 \pm 0.4^{\mathrm{AB}}$ & $7.20 \pm 0.62^{\mathrm{bc}}$ & $6.72 \pm 0.48^{\mathrm{b}}$ & $6.13 \pm 0.51^{\mathrm{a}}$ & $7.13 \pm 0.31^{\mathrm{c}}$ & $7.18 \pm 0.66^{\mathrm{c}}$ \\
\hline ABTS & $78.29 \pm 6.25^{\mathrm{A}}$ & $75.85 \pm 7.46^{\mathrm{A}}$ & $76.97 \pm 8.13^{\mathrm{A}}$ & $77.73 \pm 6.98^{\mathrm{A}}$ & $84.98 \pm 4.22^{\mathrm{d}}$ & $82.27 \pm 3.38^{c}$ & $77.14 \pm 4.84^{\text {bd }}$ & $70.85 \pm 2.75^{\mathrm{a}}$ & $70.79 \pm 5.71^{\mathrm{ab}}$ \\
\hline $\mathrm{L}^{*}$ & $29.49 \pm 0.41^{\mathrm{A}}$ & $29.51 \pm 0.57^{\mathrm{A}}$ & $29.39 \pm 0.35^{\mathrm{A}}$ & $29.34 \pm 0.50^{\mathrm{A}}$ & $29.22 \pm 0.28^{\mathrm{ab}}$ & $29.56 \pm 0.40^{\mathrm{b}}$ & $29.67 \pm 0.62^{b}$ & $29.47 \pm 0.44^{\mathrm{ab}}$ & $29.24 \pm 0.39^{\mathrm{a}}$ \\
\hline$a^{*}$ & $3.68 \pm 0.22^{\mathrm{A}}$ & $4.08 \pm 0.23^{\mathrm{B}}$ & $4.40 \pm 0.41^{\mathrm{C}}$ & $5.54 \pm 0.39^{\mathrm{D}}$ & $4.82 \pm 0.77^{\mathrm{d}}$ & $4.57 \pm 0.75^{\mathrm{c}}$ & $4.49 \pm 0.86^{\mathrm{cd}}$ & $4.15 \pm 0.64^{b}$ & $4.09 \pm 0.60^{\mathrm{a}}$ \\
\hline $\mathrm{b}^{*}$ & $-0.46 \pm 0.19^{\mathrm{A}}$ & $-0.35 \pm 0.06^{\mathrm{A}}$ & $-0.3 \pm 0.16^{\mathrm{A}}$ & $0.01 \pm 0.09^{\mathrm{B}}$ & $-0.21 \pm 0.23^{\mathrm{a}}$ & $-0.22 \pm 0.31^{\mathrm{a}}$ & $-0.27 \pm 0.18^{\mathrm{a}}$ & $-0.35 \pm 0.18^{\mathrm{a}}$ & $-0.32 \pm 0.17^{\mathrm{a}}$ \\
\hline$\Delta \mathrm{E}$ & $0.66 \pm 0.25^{\mathrm{A}}$ & $0.76 \pm 0.41^{\mathrm{A}}$ & $0.92 \pm 0.34^{\mathrm{A}}$ & $0.99 \pm 1.24^{\mathrm{A}}$ & - & $0.85 \pm 1.26^{\mathrm{a}}$ & $0.78 \pm 0.40^{\mathrm{a}}$ & $0.85 \pm 0.32^{\mathrm{a}}$ & $0.84 \pm 0.32^{\mathrm{a}}$ \\
\hline \multicolumn{10}{|c|}{ Sensory attributes } \\
\hline Hue & $20 * \mathrm{~A}$ & $24.7 \pm 7.2^{\mathrm{B}}$ & $27.2 \pm 9.5^{\mathrm{B}}$ & $38.3 \pm 15.7^{\mathrm{C}}$ & $22.6 \pm 7.4^{\mathrm{a}}$ & $29.1 \pm 14.1^{\mathrm{ab}}$ & $27.4 \pm 12.4^{\mathrm{ab}}$ & $32.4 \pm 13.8^{b}$ & $26.5 \pm 8.3^{\mathrm{ab}}$ \\
\hline $\begin{array}{l}\text { General } \\
\text { odour } \\
\text { intensity }\end{array}$ & $60 * \mathrm{~A}$ & $64.4 \pm 9.9^{\mathrm{B}}$ & $58.8 \pm 10.3^{\mathrm{A}}$ & $56.4 \pm 13.1^{\mathrm{A}}$ & $62.6 \pm 13.1^{\mathrm{a}}$ & $58.4 \pm 8.8^{\mathrm{a}}$ & $60.9 \pm 7.1^{\mathrm{a}}$ & $59.6 \pm 11.7^{\mathrm{a}}$ & $57.8 \pm 8.0^{\mathrm{a}}$ \\
\hline $\begin{array}{c}\text { Black- } \\
\text { berry } \\
\text { odour }\end{array}$ & $60 * \mathrm{BC}$ & $63.7 \pm 10.1^{\mathrm{C}}$ & $56.7 \pm 11.6^{\mathrm{AB}}$ & $56.0 \pm 9.4^{\mathrm{A}}$ & $61.0 \pm 8.7^{\mathrm{ab}}$ & $55.6 \pm 10.9^{\mathrm{a}}$ & $60.3 \pm 9.4^{b}$ & $58.5 \pm 10.6^{\mathrm{ab}}$ & $59.6 \pm 6.3^{\mathrm{ab}}$ \\
\hline $\begin{array}{l}\text { Sweet } \\
\text { odour }\end{array}$ & $30 * \mathrm{~A}$ & $37.4 \pm 14.4^{\mathrm{B}}$ & $36.2 \pm 11.5^{\mathrm{B}}$ & $31.4 \pm 7.7^{\mathrm{AB}}$ & $36.7 \pm 12.6^{\mathrm{a}}$ & $32.4 \pm 7.3^{\mathrm{a}}$ & $34.6 \pm 11.3^{\mathrm{a}}$ & $33.5 \pm 10.5^{\mathrm{a}}$ & $31.6 \pm 9.1^{\mathrm{a}}$ \\
\hline Stickiness & $40 * \mathrm{~A}$ & $44.8 \pm 11.6^{\mathrm{AB}}$ & $46.4 \pm 12.2^{\mathrm{B}}$ & $46.0 \pm 15.9^{\mathrm{B}}$ & $45.3 \pm 10.8^{b}$ & $45.6 \pm 10.4^{\mathrm{b}}$ & $47.1 \pm 16.1^{\mathrm{ab}}$ & $44.5 \pm 10.8^{\mathrm{ab}}$ & $39.1 \pm 8.3^{\mathrm{a}}$ \\
\hline $\begin{array}{l}\text { General } \\
\text { taste } \\
\text { inten- } \\
\text { sity }\end{array}$ & $60 *^{\mathrm{B}}$ & $62.3 \pm 10.2^{\mathrm{B}}$ & $60.2 \pm 11.4^{\mathrm{B}}$ & $53.2 \pm 13.9^{\mathrm{A}}$ & $58.1 \pm 10.1^{\mathrm{a}}$ & $58.9 \pm 10.0^{\mathrm{a}}$ & $62.1 \pm 10.6^{\mathrm{a}}$ & $59.4 \pm 13.4^{\mathrm{a}}$ & $56.2 \pm 9.1^{\mathrm{a}}$ \\
\hline $\begin{array}{l}\text { Black- } \\
\text { berry } \\
\text { flavour }\end{array}$ & $55^{* \mathrm{~B}}$ & $58.3 \pm 9.1^{\mathrm{C}}$ & $56.0 \pm 8.4^{\mathrm{BC}}$ & $45.1 \pm 13.1^{\mathrm{A}}$ & $54.5 \pm 6.4^{\mathrm{b}}$ & $53.5 \pm 11.4^{\mathrm{ab}}$ & $57.5 \pm 12.5^{b}$ & $49.7 \pm 11.0^{\mathrm{a}}$ & $52.7 \pm 7.7^{\mathrm{ab}}$ \\
\hline $\begin{array}{r}\text { Sweet } \\
\text { taste }\end{array}$ & $40 * \mathrm{~A}$ & $46.5 \pm 12.5^{\mathrm{B}}$ & $45.7 \pm 12.0^{\mathrm{AB}}$ & $48.1 \pm 16.7^{\mathrm{B}}$ & $46.9 \pm 16.4^{\mathrm{a}}$ & $44.4 \pm 11.4^{\mathrm{a}}$ & $47.3 \pm 12.5^{\mathrm{a}}$ & $42.7 \pm 11.9^{\mathrm{a}}$ & $44.0 \pm 7.9^{\mathrm{a}}$ \\
\hline Sour taste & $40^{* \mathrm{~A}}$ & $48.3 \pm 12.4^{\mathrm{BC}}$ & $49.3 \pm 14.9^{\mathrm{C}}$ & $41.0 \pm 12.4^{\mathrm{AB}}$ & $47.2 \pm 11.4^{\mathrm{a}}$ & $45.5 \pm 12.2^{\mathrm{a}}$ & $43.4 \pm 13.6^{\mathrm{a}}$ & $46.2 \pm 12.2^{\mathrm{a}}$ & $41.0 \pm 10.6^{\mathrm{a}}$ \\
\hline
\end{tabular}

*pre-set reference values

Mean \pm standard deviation. Superscript letters show significant differences $(p<0.05)$ between jams for different sweeteners and storage time: capital letters refer to sweetener models, lowercase letters refer to storage time models 
jams prepared with sugar alcohols obtained significantly lower scores for general odour intensity and blackberry odour than those containing fructose. Both fructose- and sucrose-based samples were superior to erythritol-sweetened jams in terms of blackberry odour. Fructose-containing samples were also superior to sucrose-sweetened samples in terms of their blackberry flavour. Erythritol-containing samples were inferior to the rest of the samples regarding general taste intensity and blackberry flavour. The low values obtained by erythritol for blackberry flavour and general taste intensity are in accordance with those reported by Hwang et al. (2014), who did not recommend erythritol to be used as sole sweetener, because it influenced the sensory properties negatively [37]. However, erythritol- and fructose-containing samples were sweeter than sucrose-based jams. The differences detected among the organoleptic properties of our blackberry jams did not confirm entirely the literature reporting no significant sensory differences between sugar- and xylitol-based fruit products [40]. Fructose- and xylitol-containing samples had a more intensive sweet odour than the sucrose-containing ones. On the other hand, xylitolsweetened jams were perceived as being significantly sourer than erythritol- and sucrose-based jams, and while sucrosecontaining samples were less sour than the fructose-containing ones. Finally, the use of sugar alcohols resulted in jams that were stickier than the sucrose-containing samples.

Regarding the effect of the storage time, only hue, blackberry odour and flavour, and stickiness went through significant changes $(p<0.05)$. Samples stored for 6 months were significantly more reddish compared to the fresh samples. Moreover, samples stored for six months were significantly weaker in blackberry flavour compared to 1- and 3-monthold samples. Jams stored for 1 month were perceived as having less intense blackberry odour compared to 3-month-old jams. Panellists in our study responded in the open-ended text fields that the erythritol samples showed a grainy, sandy texture. In addition, the samples at the endpoint were significantly less sticky than the fresh jams and jams stored for 1 month.

To identify specific patterns in our sensory data matrix, multiple factor analysis (MFA) was applied (Fig. 3). MFA performs individual PCAs on the data matrices obtained from the five sensory evaluation sessions. Figure $3 \mathrm{a}$ presents the scores plot of the MFA containing the results of all the sessions. Erythritol-containing samples are located on the left side of the plot and are not overlapped by fructose or sucrose-containing samples. Xylitol-based samples overlap with all other samples, while fructose samples are clearly different from erythritol-sweetened samples. A clear left-right differentiation is seen on Fig. 3a along with F1, in which colour, global odour and taste intensity proved to be the major contributors from the five data sets. Based on these results, we conclude that fructose- and erythritol-based
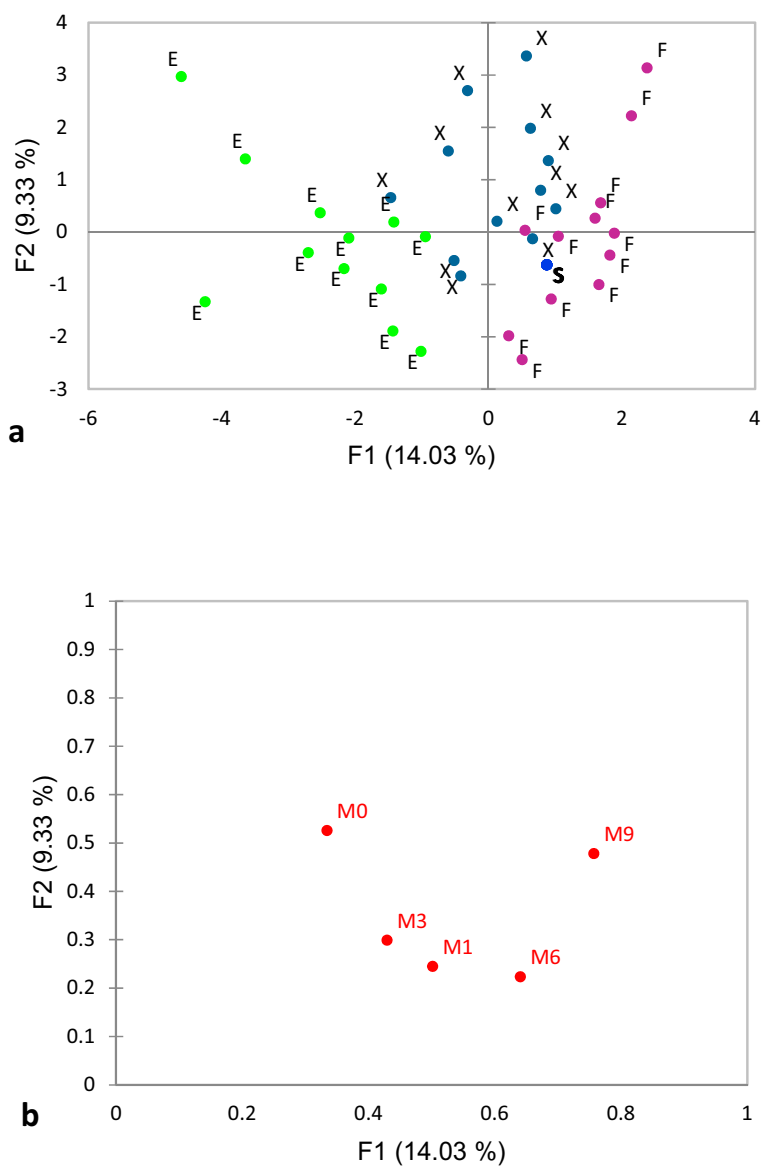

Fig. 3 Multiple factor analysis scores plot (a) and table coordinate plot (b). $E$ erythritol, $S$ sucrose, $F$ fructose, $X$ xylitol, $M$ denotes months, while numbers after $\mathrm{M}$ denote the number of months elapsed from preparation

samples showed different sensory properties. Figure $3 b$ presents the connections among the different data sets. In a similar manner to Fig. 3a, clear trend can be seen along F1, meaning that sensory attributes changed not only among samples but during storage, too.

Although there are many reports available on the use of electronic nose and tongue in quality monitoring of fruits and processed fruit products $[48,49]$, there are only a few reports discussing experiments on jams, most of the papers focusing on fruit juices or nectars [50,51]. Generally, these tools showed good performances in differentiating variously processed fruit products, including thermal processing. Electronic tongue shows better performance in most of the cases.

In line with literature reports, linear discriminant analysis (LDA) performed on electronic tongue results (Fig. 4) provided a correct classification (100\%) for each group of the freshly prepared jams (month 0 ) according to their sweetening agent. The same correct classification was obtained at the end of the storage period (100\%). Distances show that sugar-based preparations are more similar to each other than 


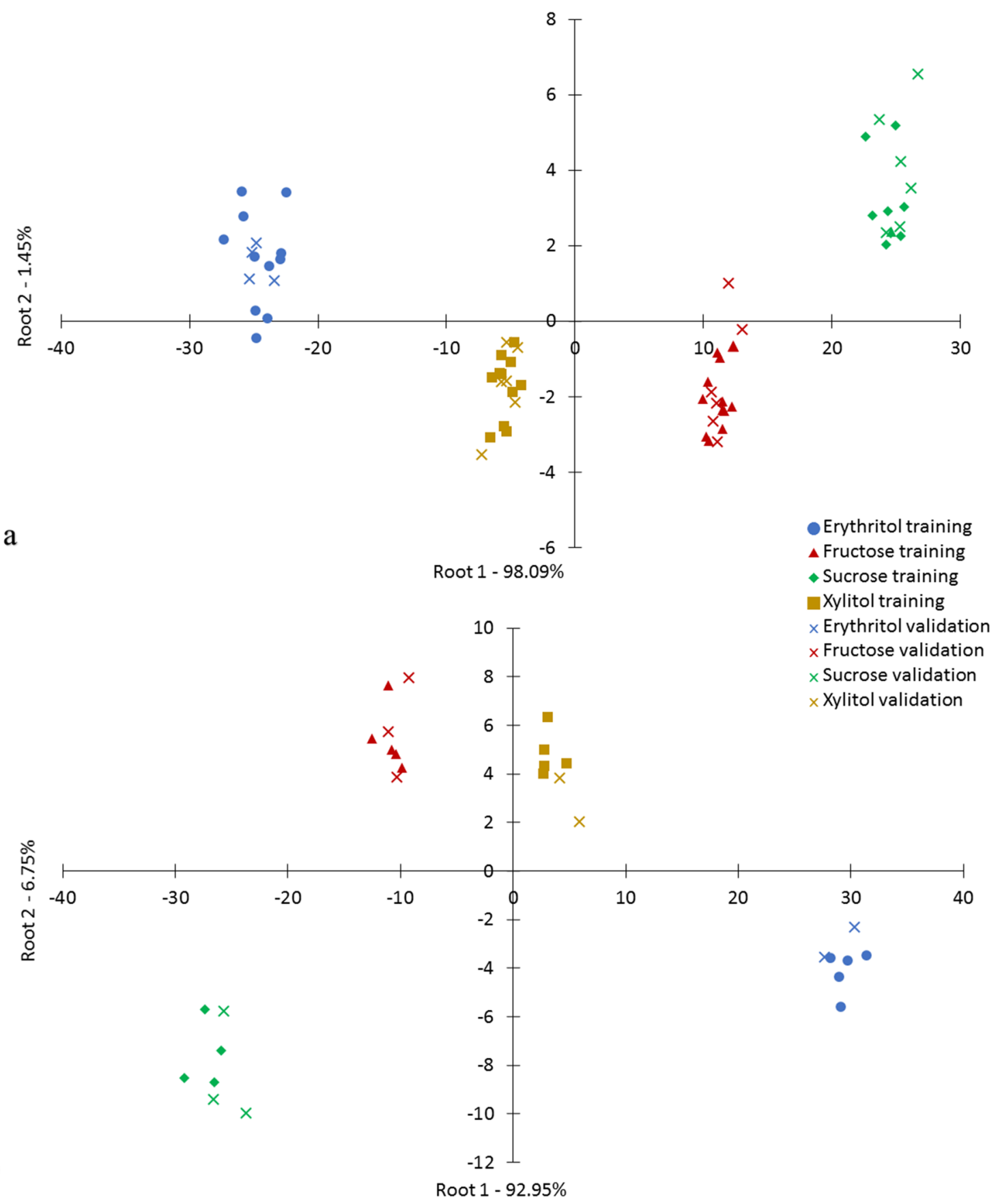

Fig. 4 Linear discriminant analysis (LDA) performed on electronic tongue results in month 0 (a) and month 9 (b)

those with sugar-alcohols. Due to the drift correction, discriminant analysis according to the sweetener can be done for the whole storage period, this leading again to a fully correct classification [52, 53].

On the other hand, LDA of the results obtained by the electronic nose (Fig. 5) provided no differentiation according to the sweetener used, this suggesting differences rather in taste than in the odour of the jams prepared with different sweeteners. Classification models built according to sweetener type provided average recognition and prediction abilities of $63.97 \%$ and $36.42 \%$, respectively, in month 0 . Measurement points of samples with erythritol or fructose were misclassified into all the other groups; points of the sample with xylitol were misclassified as the sample groups containing fructose and erythritol, while sucrosebased jams were misclassified only into the xylitol-based class. For month 9 the average recognition and prediction abilities were $71.60 \%$ and $40.98 \%$, respectively. The 


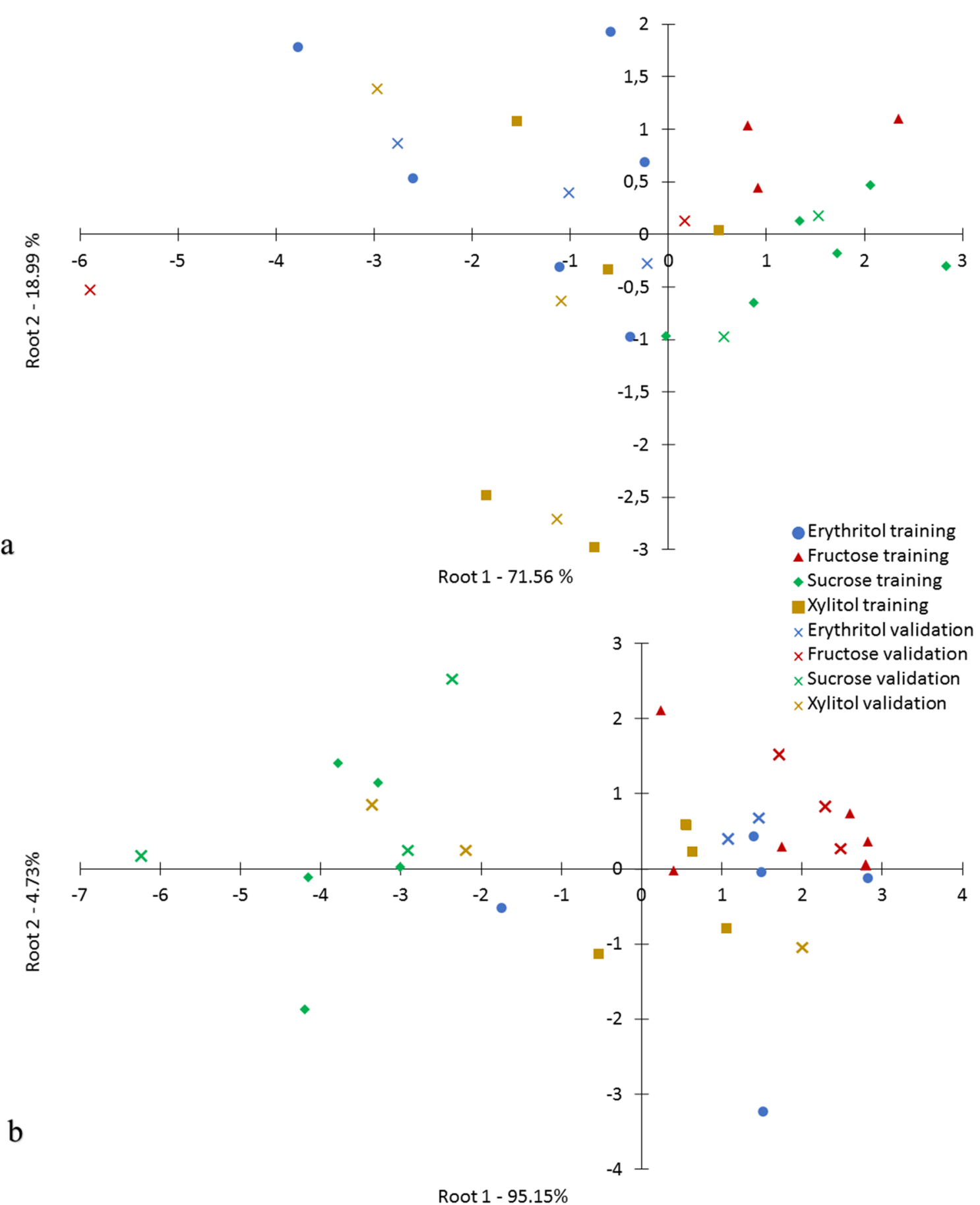

Root $1-95.15 \%$

Fig. 5 Linear discriminant analysis (LDA) performed on electronic nose results in month 0 (a) and month 9 (b)

results obtained showed a serious misclassification for sample group with erythritol, being classified as fructose(71.37\%) and xylitol-sweetened (28.63\%) sample groups. Fructose-containing jams were misclassified as $11 \%$ belonging to xylitol-containing class, while xylitol was misclassified into all the other groups, and sucrose was misclassified as erythritol (12.36\%) and xylitol (25.09\%) sample groups. 


\section{Conclusions}

Evaluation of blackberry jams prepared with different sweeteners (sucrose, fructose, xylitol, erythritol) during 9-months storage revealed a series of significant differences in terms of antioxidant properties, polyphenol content, colour and sensory attributes. Thus, the type of sweetener had a measurable impact on the evolution of both sensory attributes and antioxidant properties. Storage time also had a well-defined effect on sensory and compositional properties of jams.

Antioxidant capacities and total polyphenol content did not change according to a consistent trend during the investigation period, this was most probably attributed to the formation of Maillard reaction products and polymeric compounds. Due to the complex processes occurring, changes in total polyphenol content measured by Folin-Ciocalteu assay were not in accordance with the decay of the individual native phenolic compounds determined by LC-MS, therefore, it was concluded that the Folin assay cannot be considered as an efficient tool in monitoring polyphenol degradation during storage of jams. Regarding anthocyanin degradation, fructose proved to produce the highest decomposition rate, while the reaction was the slowest in xylitolcontaining jams.

Colorimetric measurements revealed that erythritol-containing jams were significantly higher in red hue than all the other studied jams. Similarly, when compared by a trained sensory panel, the jams sweetened with erythritol were perceived as having been the most reddish. These findings suggest that anthocyanin concentration per se is not the only significant determinant of the characteristic reddish colour of blackberry jams. It is noted, however, that erythritol-containing jams obtained the lowest intensity scores for general taste intensity and blackberry flavour. On the other hand, fructose reached positive results in general odour intensity and blackberry flavour. Unlike the electronic nose, electronic tongue produced a correct classification according to the type of sweetener and time, this qualifying it as a potential tool applicable in the food industry for monitoring the sensory properties of fruit jams with different sweeteners, as well as the alteration of these characteristics during storage.

Taking into consideration the positive effects that xylitol showed on anthocyanin decay, as well as its sensory scores that were not significantly lower than those obtained for sucrose, it can be concluded that xylitol may be eligible as a good alternative for diet jams. Although erythritol showed good performance in preserving the appealing red hue of the jams produced, its other important sensory attributes lagged behind those obtained by sugars or by xylitol.

Acknowledgements Open access funding provided by Semmelweis University.
Author contributions CsB drafted the manuscript, performed antioxidant measurements and coordinated the study, ZB and VTM executed laboratory measurements, ZB performed statistical calculations, $\mathrm{Z}$. Kókai and AG performed sensory profile analysis and contributed to statistical calculations, ID performed electronic nose measurements, Z. Kovacs performed electronic tongue measurements, LA performed LC-MS measurements and made extensive revisions on the manuscript. All the authors have reviewed and approved the final article.

Funding Supported by the Doctoral School of Food Science, Szent István University. Supported by the ÚNKP-19-3-I-SZIE-71 (Zs.B.) and ÚNKP-19-4 (LA, ZK) New National Excellence Program of the Ministry for Innovation and Technology. Supported by the Janos Bolyai Scholarship of the Hungarian Academy of Sciences (LA, ZK). LA acknowledges the support EFOP-3.6.3-VEKOP-16-2017-00005 and VEKOP-2.3.3-15-2017-00022 grants of the European Union cofinanced by the European Social Fund. AG was supported by the Premium Postdoctoral Researcher Program of the Hungarian Academy of Sciences.

\section{Compliance with ethical standards}

Conflicts of interest The authors declare that they have no conflict of interest.

Compliance with ethics requirements This article does not contain any studies with human participants or animals performed by any of the authors.

Availability of data and material Not applicable.

Code availability Not applicable.

Open Access This article is licensed under a Creative Commons Attribution 4.0 International License, which permits use, sharing, adaptation, distribution and reproduction in any medium or format, as long as you give appropriate credit to the original author(s) and the source, provide a link to the Creative Commons licence, and indicate if changes were made. The images or other third party material in this article are included in the article's Creative Commons licence, unless indicated otherwise in a credit line to the material. If material is not included in the article's Creative Commons licence and your intended use is not permitted by statutory regulation or exceeds the permitted use, you will need to obtain permission directly from the copyright holder. To view a copy of this licence, visit http://creativecommons.org/licenses/by/4.0/.

\section{References}

1. Lee J (2015) Sorbitol, Rubus fruit, and misconception. Food Chem 166:616-622. https://doi.org/10.1016/j.foodchem.2014.06.073

2. Ruiz-Ojeda FJ, Plaza-Díaz J, Sáez-Lara MJ, Gil A (2019) Effects of Sweeteners on the Gut Microbiota: a review of experimental studies and clinical trials. Adv Nutr 10:S31-S48. https://doi. org/10.1093/advances/nmy037

3. Jensen T, Abdelmalek MF, Sullivan S et al (2018) Fructose and sugar: a major mediator of non-alcoholic fatty liver disease. J Hepatol 68:1063-1075. https://doi.org/10.1016/j. jhep.2018.01.019

4. Williamson $\mathrm{G}$ (2017) The role of polyphenols in modern nutrition. Nutr Bull 42:226-235 
5. Fraga CG, Croft KD, Kennedy DO, Tomás-Barberán FA (2019) The effects of polyphenols and other bioactives on human health. Food Funct 10:514-528. https://doi.org/10.1039/c8fo01997e

6. Hein S, Whyte AR, Wood E et al (2019) Systematic review of the effects of blueberry on cognitive performance as we age. J Gerontol Ser A Biol Sci Med Sci 74:984-995

7. Kårlund A, Moor U, Sandell M, Karjalainen RO (2014) The impact of harvesting, storage and processing factors on healthpromoting phytochemicals in berries and fruits. Processes 2:596624. https://doi.org/10.3390/pr2030596

8. Dzhambazova T, Badjakov I, Dincheva I et al (2014) New approaches for detection of unique qualities of small fruits. Omi Technol Crop Improv 2:187-208. https://doi.org/10.1201/b1757 3-9

9. Olivas-Aguirre FJ, Rodrigo-García J, Martínez-Ruiz NDR et al (2016) Cyanidin-3-O-glucoside: physical-chemistry, foodomics and health effects. Molecules 21:1-30. https://doi.org/10.3390/ molecules21091264

10. Nayak B, Liu RH, Tang J (2015) Effect of processing on phenolic antioxidants of fruits, vegetables, and grains-a review. Crit Rev Food Sci Nutr 55:887-919. https://doi.org/10.1080/10408 398.2011.654142

11. Brandão TM, Do Carmo EL, Elias HES et al (2018) Physicochemical and microbiological quality of dietetic functional mixed cerrado fruit jam during storage. Sci World J. https://doi. org/10.1155/2018/2878215

12. Szalóki-Dorkó L, Stéger-Máté M, Abrankó L (2016) Effects of fruit juice concentrate production on individual anthocyanin species in elderberry. Int J Food Sci Technol 51(3):641-648. https:// doi.org/10.1111/ijfs.13031

13. Belitz HD, Grosch W, Schieberle P (2009) Food Chemistry, 4th edn. Springer, Berlin/Heidelberg

14. European Commission (2014) Commission implementing regulation (EU) laying down the refractometry method of measuring dry soluble residue in products processed from fruit and vegetables for the purposes of their classification in the Combined Nomenclature. Off J 27(4):6-10

15. Singleton VL, Rossi JA (1965) Colorimetry of Total Phenolics with Phosphomolybdic-Phosphotungstic acid reagents. Am J Enol Vitic 16:144-158

16. Lee J, Durst RW, Wrolstad RE (2005) Determination of total monomeric anthocyanin pigment content of fruit juices, beverages, natural colorants, and wines by the $\mathrm{pH}$ differential method: collaborative study. J AOAC Int 88:1269-1278

17. Re R, Pellegrini N, Proteggente A et al (1999) Antioxidant activity applying an improved ABTS radical cation decolorization assay. Free Radic Biol Med 26:1231-1237. https://doi.org/10.1016/ S0891-5849(98)00315-3

18. García-Viguera C, Zafrilla P, Romero F et al (1999) Color stability of strawberry jam as affected by cultivar and storage temperature. J Food Sci 64:243-247. https://doi.org/10.1111/j.1365-2621.1999. tb15874.x

19. Smanalieva J, Salieva K, Borkoev B et al (2015) Investigation of changes in chemical composition and rheological properties of Kyrgyz rice cultivars (Ozgon rice) depending on long-term stackstorage after harvesting. LWT Food Sci Technol 63(1):626-632. https://doi.org/10.1016/j.lwt.2015.03.045

20. International Organization for Standardization (1994) Sensory analysis-Identification and selection of descriptors for establishing a sensory profile by a multidimensional approach (ISO Standard No. 11035:1994). Retrieved from https://www.iso.org/ standard/19015.html

21. International Organization for Standardization (2012) Sensory analysis - General guidelines for the selection, training and monitoring of selected assessors and expert sensory assessors (ISO
Standard No. 8586:2012). Retrieved from https://www.iso.org/ standard/45352.html

22. International Organization for Standardization (2016) Sensory analysis-Methodology_-General guidance for establishing a sensory profile (ISO Standard No. 13299:2016). Retrieved from https://www.iso.org/standard/58042.html

23. International Organization for Standardization (2007) Sensory analysis-General guidance for the design of test rooms (ISO Standard No. 8589:2007). Retrieved from https://www.iso.org/ standard/36385.html

24. Kókai Z, Heszberger J, Kollár-Hunek K et al (2004) ProfiSens - a profile analysis supporting software in food industry, related research and education. Period Polytech Chem Eng 48(1):31-41

25. Alpha M.O.S. (2003) $\alpha$ Astree electronic tongue user manual. Toulouse, France

26. Abrankó L, Clifford MN (2017) An Unambiguous nomenclature for the acyl-quinic acids commonly known as chlorogenic acids. J Agric Food Chem 65:3602-3608. https://doi.org/10.1021/acs. jafc.7b00729

27. IUPAC (1976) Nomenclature of cyclitols. Eur J Biochem 153:2331. https://doi.org/10.1016/0005-2760(87)90273-6

28. Field A (2013) Discovering Statistics using IBM SPSS Statistics, 4th edn. Sage Publications Ltd., London, England

29. Szöllősi D (2015) Analysis of taste interactions with the electronic tongue. Corvinus University of Budapest, Budapest

30. Addinsoft (2020) XLSTAT statistical and data analysis solution. Long Island, NY, USA. https://www.xlstat.com

31. Kamiloglu S, Pasli AA, Ozcelik B et al (2015) Colour retention, anthocyanin stability and antioxidant capacity in black carrot (Daucus carota) jams and marmalades: Effect of processing, storage conditions and in vitro gastrointestinal digestion. J Funct Foods 13:1-10. https://doi.org/10.1016/j.jff.2014.12.021

32. Sokół-Łetowska A, Kucharska AZ, Szumny A et al (2018) Phenolic composition stability and antioxidant activity of sour cherry liqueurs. Molecules 23:2156. https://doi.org/10.3390/molecules2 3092156

33. Howard LR, Castrodale C, Brownmiller C et al (2010) Jam processing and storage effects on blueberry polyphenolics and antioxidant capacity. J Agric Food Chem 58:4022-4029. https ://doi.org/10.1021/jf902850h

34. Palav TS (2016) Chemistry of Cake Manufacturing. In: Smithers GW (ed) Reference Module in Food Science. Elsevier, Amsterdam

35. Shalaby EA, Ghada IM, Shanab SMM (2016) Suggested mechanism for the effect of sweeteners on radical scavenging activity of phenolic compounds in black and green tea. Front Life Sci 9(4):241-251. https://doi.org/10.1080/21553769.2016.1233909

36. Madrau MA, Piscopo A, Sanguinetti AM et al (2009) Effect of drying temperature on polyphenolic content and antioxidant activity of apricots. Eur Food Res Technol 228:441-448. https://doi. org/10.1007/s00217-008-0951-6

37. Hwang ES, Tai ND (2014) Quality characteristics and antioxidant activities of aronia jam replacing sucrose with different sugar substances. Korean J Food Nutr 27:888-896

38. Stamatovska V, Nakov G, Babanovska-Milenkovska F, Kalevska $\mathrm{T}$ (2018) Change of anthocyanins content during production of jam from different species of fruit 9th International Congress of Food Technologists. Biotechnologists and Nutritionists, Zagreb, Croatia

39. Nowicka P, Wojdylo A (2016) Stability of phenolic compounds, antioxidant activity and colour through natural sweeteners addition during storage of sour cherry puree. Food Chem 196:925934. https://doi.org/10.1016/j.foodchem.2015.10.019

40. Korus A, Banas A, Korus J (2017) Effects of plant ingredients with pro-health properties and storage conditions on texture, color and sensory attributes of strawberry (Fragaria $\times$ ananassa Duch.) 
jam. Emirates J Food Agric 29:610-619. https://doi.org/10.9755/ ejfa.2017-05-1143

41. Rababah TM, Al-U'Datt M, Al-Mahasneh M et al (2014) Effect of jam processing and storage on phytochemicals and physiochemical properties of cherry at different temperatures. J Food Process Preserv 38:247-254. https://doi.org/10.1111/j.1745-4549.2012.00770 . $\mathrm{x}$

42. de Mamede ME et al (2013) Production of dietetic jam of UmbuCaja (Spondias sp.): physical, physicochemical and sensorial evaluations. Food Nutr Sci 04:461-468. https://doi.org/10.4236/ fns.2013.44059

43. Mokrzycki W, Tatol M (2011) Color difference delta E - a survey. Machine Graph Vision 20(4):383-412

44. Vukoja J, Pichler A, Kopjar M (2019) Stability of Anthocyanins, Phenolics and Color of tart cherry jams. Foods 8:255. https://doi. org/10.3390/foods 8070255

45. Park MK (2007) Quality characteristics of strawberry jam containing sugar alcohols. Korean J Food Sci Technol 39:44-49

46. Ifie I, Abrankó L, Villa-Rodriguez JA et al (2018) The effect of ageing temperature on the physicochemical properties, phytochemical profile and $\alpha$-glucosidase inhibition of Hibiscus sabdariffa (roselle) wine. Food Chem 267:263-270. https://doi. org/10.1016/j.foodchem.2017.05.044

47. De Carvalho DA, Valente GDFS, Assumpção GMP (2018) External preference map to evaluate the acceptance of light and diet yogurt prepared using natural sweeteners. Cienc Rural 48:6. https ://doi.org/10.1590/0103-8478cr20170941

48. Teixeira FTR (2019) Mixed Brazilian Cerrado fruits preserves without added sugar: the effect of bodying agents. Br Food J 121:1969-1981. https://doi.org/10.1108/BFJ-11-2018-0739
49. Poiana MA, Alexa E, Mateescu C (2012) Tracking antioxidant properties and color changes in low-sugar bilberry jam as effect of processing, storage and pectin concentration. Chem Cent J 6:4. https://doi.org/10.1186/1752-153X-6-4

50. Gliszczyńska-Świgło A, Chmielewski J (2017) Electronic nose as a tool for monitoring the authenticity of food. A Rev Food Anal Methods 10:1800-1816. https://doi.org/10.1007/s1216 1-016-0739-4

51. Śliwińska M, Wiśniewska P, Dymerski T et al (2016) Advances in Electronic Noses and Tongues for Food Authenticity Testing in Food Science. Technology and Nutrition. Woodhead Publishing, Swaston

52. Kovacs Z, Sipos L, Szöllősi D et al (2011) Electronic tongue and sensory evaluation for sensing apple juice taste attributes. Sens Lett 9:1273-1281. https://doi.org/10.1166/sl.2011.1687

53. Qiu S, Wang J, Gao L (2014) Discrimination and characterization of strawberry juice based on electronic nose and tongue: comparison of different juice processing approaches by LDA, PLSR, RF, and SVM. J Agric Food Chem 62:6426-6434. https://doi. org/10.1021/jf501468b

Publisher's Note Springer Nature remains neutral with regard to jurisdictional claims in published maps and institutional affiliations. 